\title{
Prevalence and correlates of suicidal behaviour among adults in Malawi: a nationally representative cross-sectional survey in 2017
}

Supa Pengpid ${ }^{1,2}$ and Karl Peltzer ${ }^{3,4^{*}}$ (1)

\begin{abstract}
Background: The study aimed to assess the prevalence and associated factors of suicidal behaviour (SB) among adults in Malawi.

Methods: Data were analysed from 4187 persons aged 18-69 years (median age: 32 years) that took part in the nationally representative cross-sectional "2017 Malawi STEPS survey."

Results: The prevalence of ever suicide attempt was $0.8 \%$, and the prevalence of SB (ideation, plan and/or attempt) in the past year was 7.9\% (6.0\% among men and 9.6\% among women). In adjusted logistic regression analysis, among men, being 30 years and older and having an alcohol family problem were positively and obesity was negatively associated with SB in the past year. Moreover, in univariate analysis, early smoking initiation was positively and not using active transportation was negatively associated with SB in the past year. Among women, having an alcohol family problem, death from suicide of a close family member, having a cardiovascular incident (heart attack, stroke, or angina) and not using active transportation increased the odds of SB in the past year. In addition, in univariate analysis, low systolic blood pressure $(<100 \mathrm{mmHg}$ ), not taking antihypertensive medication, and current alcohol use were associated with past year SB.
\end{abstract}

Conclusion: Almost one in ten participants engaged in SB in the past year and several associated factors were identified that can inform intervention programmes.

Keywords: Suicide attempt, Suicidal behaviour, Risk factors, Adults, Malawi

\section{Background}

"Every year, almost 800,000 persons die from suicide, and four of five of them are from low- and middle-income countries" [1]. "For every suicide, there are many more people who attempt suicide every year." [1] To assess and monitor the national prevalence of suicidal behaviour (SB) is needed to guide suicide prevention strategies [2]. There are scanty national data on the epidemiology of SB, especially in low resourced countries in Africa [2].

*Correspondence: kfpeltzer@gmail.com

${ }^{3}$ Department of Psychology, University of the Free State, Bloemfontein, South Africa

Full list of author information is available at the end of the article
To fill this gap, this study provides an epidemiological national profile on SB among adults in Malawi, a lowincome landlocked country in Southern Africa. The agestandardized suicide rate, 10.8 per 100,000 in low-income countries and in Malawi 7.8 per 100,000 (3.2 among women and 13.7 among men) [3]. Based on six sampled districts in Malawi in 2017, "9 out of 100,000 people in Malawi commit suicide annually." [4] Malawi's total population is 21.2 million, $17.4 \%$ live in urban areas, $80 \%$ are employed in agriculture, life expectancy at birth was 63.2 years, $62.1 \%$ can read and write and most $(77.3 \%)$ are Christians by religion [5]. It has an HIV/AIDS adult prevalence rate of $9.2 \%$ and one million are living with HIV in Malawi [5].

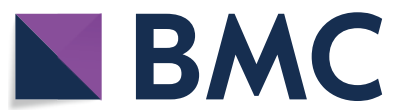

(c) The Author(s) 2021. This article is licensed under a Creative Commons Attribution 4.0 International License, which permits use, sharing, adaptation, distribution and reproduction in any medium or format, as long as you give appropriate credit to the original author(s) and the source, provide a link to the Creative Commons licence, and indicate if changes were made. The images or other third party material in this article are included in the article's Creative Commons licence, unless indicated otherwise in a credit line to the material. If material is not included in the article's Creative Commons licence and your intended use is not permitted by statutory regulation or exceeds the permitted use, you will need to obtain permission directly from the copyright holder. To view a copy of this licence, visit http://creativeco mmons.org/licenses/by/4.0/. The Creative Commons Public Domain Dedication waiver (http://creativecommons.org/publicdomain/ zero/1.0/) applies to the data made available in this article, unless otherwise stated in a credit line to the data. 
"World Mental Health Survey" data showed a lifetime prevalence of $2.9 \%$ suicide attempt in South Africa [2] and $0.7 \%$ in Nigeria [6], and the prevalence of SB in the past year was $2.1 \%$ suicidal ideation, $0.7 \%$ suicide plans, and $0.4 \%$ suicide attempts in ten low- and middleincome countries [7]. In a community study in Ethiopia, the prevalence of SB in the ypas year was $7.0 \%$ ideation, 4.6 plans, and $3.7 \%$ attempts, and among those with a suicide attempt $26.0 \%$ sought treatment [8]. Among population-based adult samples, $51.9-60.9 \%$ of those with suicidal thoughts (suicide ideation or plan) in high-income countries received treatment, 18.5-30.9\% in middle-income countries and $13.6-17.8 \%$ in lowincome countries received treatment, while for those with suicide attempts, $64.7-70.3 \%$ in high income countries received treatment, $47.9-49.1 \%$ in middleincome countries, and $14.8-48.1 \%$ in low-income countries received treatment [9].

Factors associated with SB among adults may include sociodemographic factors, having psychosocial distress, physical factors, and health risk behaviours. Sociodemographic factors associated with SB may include family history of suicide, younger age, female sex [7, $8,10]$, and lower socioeconomic status [11-13]. Psychosocial distress risk factors of SB may include mental illness, including major depression and alcohol use disorders [1], experiencing adverse life events [1, 14, 15], and unemployment [11-13]. Physical factors associated with SB may include suffering from physical chronic conditions, such as cardiovascular disease, epilepsy, and diabetes [11-13, 16, 17], hypercholesrolemia $[16,18]$ and low blood pressure [19], and health risk behaviours associated with $\mathrm{SB}$, which may include high sedentary behaviour and physical inactivity [20-22], substance use disorders [23-25], passive smoking [26, $27]$, early substance use $[28,29]$ and overweight or obesity [30, 31].

It has been hypothesised that psychosocial distress, physical factors, health risk behaviours, and sociodemographic factors are associated with SB in Malawi. The study aimed to assess for the first time the national prevalence and associated factors of SB among persons aged 18-69 years in Malawi.

\section{Methods}

Data were analysed from adults that participated in the cross-sectional nationally representative "2017 Malawi STEPS survey" [32]. Based on a multistage cluster sample design, the "2017 Malawi STEPS Survey" produced nationally representative population-based data for persons 18-69 years in Malawi [32]. The data and details of the study methodology can be publicly accessed [32].

\section{Measures}

Outcome variables included lifetime suicide attempt, SB in the past year (ideation, plan and attempt), methods used for suicide attempts, and care seeking for SB (questionnaire items are shown in Additional file 1) [32].

Sociodemographic variables included highest formal education, age, employment and marital status, and sex.

Psychosocial distress indicators were passive smoking, history of attempted suicide or death from suicide of a close family member, and alcohol family problems (details in Additional file 1) [32].

Physical factors and health risk behaviour information consisted of measured blood pressure; those who were diagnosed with hypertension were asked if they were taking antihypertensive medication in the past 2 weeks; Body Mass Index (measured " $<18.5 \mathrm{~kg} / \mathrm{m}^{2}$ underweight, $18.5-24.4 \mathrm{~kg} / \mathrm{m}^{2}$ normal weight, $25-29.9 \mathrm{~kg} /$ $\mathrm{m}^{2}$ overweight and $\geq 30 \mathrm{~kg} / \mathrm{m}^{2}$ obesity"), measured diabetes ("fasting plasma glucose levels $\geq 7.0 \mathrm{mmol} / \mathrm{L}$; or using insulin or oral hypoglycaemic drugs"); raised total cholesterol (TC) ("fasting $\mathrm{TC} \geq 5.0 \mathrm{mmol} / \mathrm{L}$ or currently on medication for raised cholesterol"); history of "heart attack or chest pain from heart disease (angina) or a stroke (cerebrovascular accident or incident)", age of smoking initiation, current smokeless tobacco consumption, current alcohol use, alcohol dependence, past month passive smoking, and based on the "Global Physical Activity Questionnaire" no active transportation ("walking or using a bicycle for at least $10 \mathrm{~min}$ to get to and from places") and sedentary behaviour ( $\geq 7 \mathrm{~h} /$ day) [32]. Alcohol dependence was sourced from three items the "Alcohol Use Disorder Identification Test=AUDIT" (items 4-6), e.g., "How often during the last year have you found that you were not able to stop drinking once you had started?" Responses ranged from " $0=$ never to $4=$ daily or almost daily". Scores were summed, with $\geq 4$ scores indicating alcohol dependence [33].

\section{Data analysis}

Statistical analyses were done with "STATA software version 15.0 (Stata Corporation, College Station, Texas, USA)," taking into account the complex study design. Unadjusted and adjusted logistic regression was utilised to estimate predictors of ever suicide attempt and SB (ideation, plan and/or attempt) in the past year. Variables found significant in univariate analyses were subsequently added in the multivariable regression model. Covariates were included based on literature review [ 1 , $10-31]$. The missing values were not included in the analysis. $\mathrm{P}<0.05$ was accepted as significant. 


\section{Results}

\section{Sample characteristics}

The sample consisted of 4,187 individuals (median age: 32 years, 18 years interquartile range, age range: 18-69 years), 51.7\% were female, $58.7 \%$ had Standard 5 or more education, $73.0 \%$ were married or cohabiting, $43.8 \%$ were employed or students, $89.1 \%$ lived in rural areas and $89.1 \%$ were Chewa speakers. Almost one in ten participants $(8.3 \%)$ reported alcohol family problems, $5.4 \%$ and $2.5 \%$ had a close family member who attempted suicide and died from suicide, respectively, and $20.7 \%$ were exposed to passive smoking. Almost one in five participants (18.5\%) were overweight/obese, $6.4 \%$ had a systolic blood pressure of $<100 \mathrm{mmHg}, 5.6 \%$ were not taking antihypertensive medications, $1.7 \%$ had prediabetes and $1.3 \%$ had diabetes, $8.2 \%$ had raised total cholesterol, $6.5 \%$ had a history of angina, heart attack, or stroke, $0.5 \%$ initiated smoking early ( $\leq 14$ years), $1.4 \%$ were current smokeless tobacco users, 5.0\% had alcohol dependence, $90.4 \%$ had inadequate intake of fruit and vegetables, $8.0 \%$ did not engage in active transportation and $5.6 \%$ engaged in sedentary behaviour (see Table 1).

\section{Suicidal behaviour characteristics}

The prevalence of ever suicide attempt was $0.8 \%$, and the prevalence of past year SB (ideation $7.2 \%$, plan $3.9 \%$, and attempt $0.4 \%)$ was $7.9 \%$ (6.0\% among men and $9.6 \%$ among women, $P<0.001$ ) (see Table 1 ). Major suicide attempt methods were to "hang on a rope" (33.3\%), "overdose of medication (e.g., prescribed, over-the-counter)" $(21.7 \%)$ and "poisoning with pesticides (e.g., rat poison, insecticide, weed-killer)" (17.2\%). Only a few participants (4.1\%) got medical treatment following the last suicide attempt, of which none was admitted to hospital. Almost one in three participants with suicidal ideation (29.5\%) had sought professional care.

\section{Associations with SB in the past year}

In adjusted logistic regression analysis, among men, being 30 years and older and having an alcohol family problem were positively and obesity was negatively associated with SB in the past year. Moreover, in univariate, early smoking initiation was positively and not using active transportation was negatively associated with SB in the past year.

Among women, having an alcohol family problem, death from suicide of a close family member, having a cardiovascular incident (heart attack, stroke, or angina), and not using active transportation were associated with $\mathrm{SB}$ in the past year. Moreover, in univariate analysis, low systolic blood pressure $(<100 \mathrm{mmHg})$, not taking antihypertensive medication, and current alcohol use were associated with SB in the past year (see Table 2).

\section{Discussion}

In this nationally representative sample of persons aged 18-69 years in Malawi, the lifetime prevalence of suicide attempts $(0.8 \%)$ was similar to national studies among adults in Nigeria (0.7\%) [6], and Bhutan (0.7\%) [10], but lower than in South Africa (2.9\%) [2]. The prevalence of $\mathrm{SB}$ in the past year $(7.2 \%$ ideation, $3.9 \%$ plans, and $0.4 \%$ attempt) in this study was higher than in ten lower resourced countries $(2.1 \%$ ideation, $0.7 \%$ plan and $0.4 \%$ attempt) [7], but similar to Ethiopia (7.0\% ideation\%, $4.6 \%$ plan and $3.7 \%$ attempt) [8]. The considerable proportion of SB in Malawi compares with a prevalence of $12.8 \%$ suicidal ideation and $12.9 \%$ suicide attempts among adolescents in Malawi [34]. The suicide rate in Malawi in 2016 (7.8 per 100,000) [3] or in 2017 (9.0 per 100,000 [4] was lower than the rate in low-income countries (10.8 per 100,000) [3]. The study found that the lifetime suicide attempt rate in Malawi was similar to Nigeria (in a study conducted from 2002-2003) [6] and Bhutan (in a study conducted in 2014) [10]. Similar socioeconomic and cultural factors [35] may play a role in the similarity of rates in these countries. Malawi is classified as a low-income country, while Nigeria and Bhutan are lower-middle income countries [36].

The study found that psychosocial distress (death of a family member from suicide and alcohol family problems) and female sex were associated with SB in the past year. Major suicide attempt methods were to "hang on a rope", "overdose of medication" and "poisoning with pesticides", which are similar to global suicides in low- and middle-income countries [1]. In a retrospective audit of suicides autopsied at a hospital in Malawi showed that the main method of suicide was chemical poisoning by agricultural pesticides [37]. "Knowledge of the most commonly used suicide methods is important to devise prevention strategies that have shown to be effective, such as restriction of access to means of suicide." [1] Among participants who reported suicidal ideation in the past year in this study, $29.5 \%$ got professional care, which is lower than in high-income countries (51.9-60.9\%) but higher than low-income countries (13.6-17.8\%) [6], and among participants with a suicide attempt, $4.1 \%$ got medical treatment which is much lower than in highincome countries (64.7-70.3\%), middle-income countries (47.9-49.1\%), and low-income countries (14.8-48.1\%) [9]. People with mental illness may experience stigma 
Table 1 Sample and suicidal behaviour characteristics among 1486 men and 2702 women aged 18-69 years in Malawi

\begin{tabular}{|c|c|c|c|}
\hline \multirow[t]{3}{*}{ Variable } & \multirow{3}{*}{$\begin{array}{l}\text { Total sample } \\
\mathrm{N}(\%)\end{array}$} & \multicolumn{2}{|c|}{ Suicidal behaviour (past 12 months) } \\
\hline & & \multirow{2}{*}{$\begin{array}{l}\text { Men } \\
\mathrm{N}(\%)\end{array}$} & \multirow{2}{*}{$\begin{array}{l}\text { Women } \\
\text { N (\%) }\end{array}$} \\
\hline & & & \\
\hline \multicolumn{4}{|l|}{ Socio-demographics } \\
\hline All & 4187 & $92(6.0)$ & $239(9.6)$ \\
\hline \multicolumn{4}{|l|}{ Age (years) } \\
\hline $18-29$ & $1371(45.5)$ & $16(2.7)$ & $85(8.9)$ \\
\hline $30-49$ & $1890(39.7)$ & $55(9.6)$ & $106(10.3)$ \\
\hline $50-69$ & $926(14.7)$ & $21(6.6)$ & $48(10.0)$ \\
\hline \multicolumn{4}{|l|}{ Education } \\
\hline Secondary or more & $1057(24.7)$ & $29(6.4)$ & $44(7.8)$ \\
\hline Standard 5-8 & $1227(34.0)$ & $34(5.4)$ & $77(12.1)$ \\
\hline Standard 1-4 & $1318(31.3)$ & $27(5.6)$ & $89(10.0)$ \\
\hline None & $581(10.0)$ & $2(9.8)$ & $28(5.5)$ \\
\hline \multicolumn{4}{|l|}{ Marital status } \\
\hline Never married & $418(14.4)$ & $11(5.4)$ & $11(6.0)$ \\
\hline Married/cohabiting & $2888(73.0)$ & $70(6.4)$ & $152(9.7)$ \\
\hline Separated/divorced/widowed & $866(12.6)$ & $11(3.2)$ & $76(11.2)$ \\
\hline \multicolumn{4}{|l|}{ Employment status } \\
\hline Nonpaid or unemployed & $2329(56.2)$ & $29(5.3)$ & $167(10.5)$ \\
\hline Employed or student & $1756(43.8)$ & $62(6.5)$ & $70(7.7)$ \\
\hline \multicolumn{4}{|l|}{ Residence } \\
\hline Rural & $3343(89.1)$ & $82(6.1)$ & $188(9.5)$ \\
\hline Urban & $844(10.9)$ & $10(5.2)$ & $51(10.2)$ \\
\hline \multicolumn{4}{|l|}{ Language of interview } \\
\hline Tumbuka & $145(4.3)$ & $3(6.2)$ & $4(5.4)$ \\
\hline Chewa & $3535(78.3)$ & $62(5.5)$ & $193(9.2)$ \\
\hline English & $506(17.5)$ & $27(8.0)$ & $42(12.7)$ \\
\hline \multicolumn{4}{|l|}{ Psychosocial distress } \\
\hline Alcohol family problem & $294(8.3)$ & $27(19.1)$ & $27(23.0)$ \\
\hline Family member attempted suicide & $172(5.4)$ & $9(6.0)$ & $20(22.8)$ \\
\hline Family member died from suicide & $96(2.5)$ & $4(3.2)$ & $13(27.6)$ \\
\hline Passive smoking & $700(20.7)$ & $23(8.7)$ & $44(12.2)$ \\
\hline \multicolumn{4}{|l|}{ Physical factors and risk behaviours } \\
\hline Systolic blood pressure (<100 mmHg) & $289(6.4)$ & $7(14.8)$ & $19(8.9)$ \\
\hline Not taking anti-hypertension medication & $301(5.6)$ & $2(2.4)$ & $34(15.3)$ \\
\hline \multicolumn{4}{|l|}{ Body mass index } \\
\hline Normal & $2756(73.0)$ & $65(5.9)$ & $151(10.2)$ \\
\hline Underweight & $277(8.5)$ & $11(4.1)$ & $16(18.1)$ \\
\hline Overweight & $655(13.5)$ & $12(6.9)$ & $34(7.6)$ \\
\hline Obesity & $319(5.0)$ & $3(1.4)$ & 22 97.1) \\
\hline \multicolumn{4}{|l|}{ Diabetes status } \\
\hline No & $3590(97.0)$ & $77(5.6)$ & $203(9.1)$ \\
\hline Prediabetes & $103(1.7)$ & $2(6.7)$ & $9(19.7)$ \\
\hline Diabetes & $73(1.3)$ & $3(11.5)$ & $5(11.2)$ \\
\hline Raised total cholesterol & $457(8.2)$ & $9(10.0)$ & $27(6.0)$ \\
\hline Heart attack, angina or stroke & $312(6.5)$ & $7(5.5)$ & $38(18.6)$ \\
\hline Early smoking initiation ( $\leq 14$ years) & $26(0.5)$ & $4(34.4)$ & $1(17.6)$ \\
\hline Current smokeless tobacco use & $78(1.4)$ & $1(1.1)$ & $9(16.7)$ \\
\hline Current alcohol use & $558(17.3)$ & $34(7.6)$ & $11(19.4)$ \\
\hline Alcohol dependence & $152(5.0)$ & $10(9.5)$ & $2(7.7)$ \\
\hline No active transport & $365(8.0)$ & $5(2.0)$ & $44(19.6)$ \\
\hline Sedentary behaviour & $233(5.6)$ & $10(12.7)$ & $16(10.6)$ \\
\hline
\end{tabular}


Table 1 (continued)

${ }^{a}$ Suicidal ideation and/or suicide plan and/or suicide attempt

and discrimination, hindering them to access treatment and to prevent suicide [38, 39]. Globally, the most common barriers to not receiving treatment in those with SB include low perceived need in low-income countries (67\%) and in high-income countries attitudinal barriers (54\%) and low perceived need for treatment (45\%) [9]. Access to treatment for SB and/or depression may be improved by expanding primary mental health care [40]. "With severe shortages of mental health professionals in Malawi, integration of mental health into existing primary and community health services is the most feasible way of increasing access to services for people with mental health problems." [40]

In line with previous findings $[7,8,10]$, this survey showed that women and inconsistent with previous research $[7,8,10]$ that older age among men had increased odds of SB. However, in a review of studies in Africa, mixed results were found on the female or male preponderance of SB [41]. One possible reason for the higher prevalence of suicidal ideation in men 30 years and older may be related to the higher prevalence of HIV in men 30 years and older in Malawi [42]. Compared with the general population, persons with HIV "show an increased rate of suicidal ideation, suicide attempts, and completed suicide" [43]. However, we could not find significant differences in the prevalence of SB regarding education, marital status, work status, language group, and residence status, while some previous studies [7, 8, $10,11]$ found that lower socioeconomic or lower educational status increased the odds of SB.

Having a family history of suicide has been a known risk factor for $\mathrm{SB}[7,8,10]$, which was confirmed in this study in terms of death of a close family member. In agreement with previous investigations [1, 23-25, 28, 29 ], this study showed an alcohol family problem and in unadjusted analysis, early smoking initiation among men and current alcohol use among women increased the odds for SB. While some studies [29, 30] found a positive association between overweight or obesity and SB, this study found among men a negative association between obesity and SB. It is possible that in this low-income setting, being overweight is associated with greater wellbeing and thus protective against SB.
In agreement with previous studies [13, 44], having a history of cardiovascular disease was associated with SB among women. Cardiovascular disease patients may experience a higher rate of disability, which may increase their vulnerability to SB [35, 44]. The study showed in univariate analysis that systolic blood pressure $<100 \mathrm{mmHg}$ and nontaking of antihypertensive medication among women were associated with SB in the past year. In a large previous study in South Korea, systolic blood pressure $<100 \mathrm{mmHg}$ increased the odds of suicidal ideation [19]. The possible relationship between low blood pressure and SB in Africa should be the subject of further research. Contrary to former research [1618, 20-22], this Malawi survey did not find a significant association between raised total cholesterol, sedentary behaviour, diabetes and SB. However, this study found a significant positive association among women between nonuse of active transportation and SB. This result may confirm an association with one type of sedentary behaviour and SB [20-22].

\section{Study limitations}

Study limitations include the cross-sectional design of the study, which hinders us to draw causative conclusions. In addition, most of the data were assessed by self-report, which may lead to biased responses. Furthermore, certain variables, such as parental psychopathology and mental disorders of the study participants, were not assessed in Malawi STEPS survey and should be included in future research. The variable on household income was not included, because too many values were missing.

\section{Conclusion}

Findings of this nationally representative community survey of persons aged 18 to 69 years in Malawi showed that $0.8 \%$ had ever attempted suidide and that almost one in ten had engaged in SB in the past year. Several risk factors of SB for men and/or women were identified, including female sex, older age among men, alcohol family problems (both men and women), death from suicide of family members among women, history of cardiovascular disease and no active transportation among women, which may assist in designing programmes to prevent SB in the Malawian population. 
Table 2 Associations with suicidal behaviour (ideation, plan and/or attempt) in the past year

\begin{tabular}{|c|c|c|c|c|}
\hline \multirow[t]{2}{*}{ Variable } & \multicolumn{2}{|l|}{ Male } & \multicolumn{2}{|l|}{ Female } \\
\hline & $\operatorname{COR}(95 \% \mathrm{Cl})$ & AOR $(95 \% \mathrm{Cl})$ & $\operatorname{COR}(95 \% \mathrm{Cl})$ & AOR $(95 \% \mathrm{Cl})$ \\
\hline \multicolumn{5}{|l|}{ Socio-demographics } \\
\hline \multicolumn{5}{|l|}{ Age (years) } \\
\hline $18-29$ & 1 (Reference) & 1 (Reference) & 1 (Reference) & - \\
\hline $30-49$ & $3.88(1.52,9.91)^{* *}$ & $2.90(1.057 .99)^{*}$ & $1.17(0.76,1.79)$ & \\
\hline $50-69$ & $2.56(1.02,6.40)^{*}$ & $2.41(0.90,6.46)^{*}$ & $1.14(0.74,1.75)$ & \\
\hline \multicolumn{5}{|l|}{ Education } \\
\hline Secondary or more & 1 (Reference) & - & 1 (Reference) & - \\
\hline Standard 5-8 & $0.84(0.31,2.27)$ & & $1.62(0.89,2.95)$ & \\
\hline Standard 1-4 & $0.87(0.34,2.25)$ & & $1.31(0.77,2.24)$ & \\
\hline None & $1.59(0.22,11.75)$ & & $0.69(0.35,1.37)$ & \\
\hline \multicolumn{5}{|l|}{ Marital status } \\
\hline Never married & 1 (Reference) & - & 1 (Reference) & - \\
\hline Married/cohabiting & $1.20(0.34,4.27)$ & & $1.69(0.77,3.70)$ & \\
\hline Separated/divorced/widowed & $0.59(0.14,2.49)$ & & $2.00(0.80,5.02)$ & \\
\hline \multicolumn{5}{|l|}{ Employment status } \\
\hline Nonpaid or unemployed & 1 (Reference) & - & 1 (Reference) & - \\
\hline Employed or student & $1.23(0.66,2.27)$ & & $0.71(0.44,1.16)$ & \\
\hline \multicolumn{5}{|l|}{ Residence } \\
\hline Rural & 1 (Reference) & - & 1 (Reference) & - \\
\hline Urban & $0.84(0.25,2.86)$ & & $1.08(0.63,1.86)$ & \\
\hline \multicolumn{5}{|l|}{ Language of interview } \\
\hline Tumbuka & 1 (Reference) & - & 1 (Reference) & - \\
\hline Chewa & $0.88(0.17,4.57)$ & & $1.79(0.62,5.18)$ & \\
\hline English & $1.31(0.35,4.85)$ & & $2.57(0.89,7.41)$ & \\
\hline \multicolumn{5}{|l|}{ Psychosocial distress } \\
\hline Alcohol family problem & $5.09(2.51,10.31)^{* * *}$ & $5.04(2.18,11.65)^{* * *}$ & $3.11(1.49,6.49)^{* *}$ & $2.75(1.34,5.61)^{* *}$ \\
\hline Family member attempted suicide & $0.98(0.29,3.29)$ & - & $2.96(1.31,6.66)^{* *}$ & - \\
\hline Family member died from suicide & $0.50(0.10,2.44)$ & - & $3.74(1.32,10.64)^{*}$ & $3.33(1.10,10.07)^{*}$ \\
\hline Passive smoking & $1.80(0.75,4.30)$ & - & $1.38(0.88,2.18)$ & - \\
\hline \multicolumn{5}{|l|}{ Physical factors and risk behaviours } \\
\hline Systolic blood pressure $(<100$ mmHg) & $0.90(0.42,1.97)$ & - & $2.96(1.31,6.68)^{* *}$ & $0.96(0.41,2.18)$ \\
\hline Not taking anti-hypertension medication & $0.37(0.08,1.71)$ & - & $1.79(1.01,3.16)^{*}$ & $1.35(0.79,2.30)$ \\
\hline \multicolumn{5}{|l|}{ Body mass index } \\
\hline Normal & 1 (Reference) & 1 (Reference) & 1 (Reference) & - \\
\hline Underweight & $0.68(0.23,2.01)$ & $0.78(0.29,2.11)$ & $1.94(0.94,4.01)$ & \\
\hline Overweight & $1.18(0.57,2.46)$ & $1.20(0.52,2.70)$ & $0.73(0.41,1.28)$ & \\
\hline Obesity & $0.22(0.05,0.87)^{*}$ & $0.15(0.04,0.67)^{*}$ & $0.68(0.35,1.31)$ & \\
\hline \multicolumn{5}{|l|}{ Diabetes status } \\
\hline No & 1 (Reference) & - & 1 (Reference) & - \\
\hline Prediabetes & $1.20(0.24,6.13)$ & & $2.46(0.99,6.13)$ & \\
\hline Diabetes & $2.17(0.43,10.91)$ & & $1.26(0.37,4.28)$ & \\
\hline Raised total cholesterol & $1.96(0.71,5.36)$ & - & $0.59(0.35,1.01)$ & - \\
\hline Heart attack, angina or stroke & $0.90(0.30,2.68)$ & - & $2.36(1.28,4.33)^{* *}$ & $2.07(1.17,3.66)^{*}$ \\
\hline Early smoking initiation ( $\leq 14$ years) & $8.60(2.03,36.45)^{* *}$ & $6.20(0.75,51.16)$ & $2.01(0.21,19.27)$ & - \\
\hline Current smokeless tobacco use & $0.17(0.02,1.58)$ & - & $1.91(0.89,4.14)$ & - \\
\hline Current alcohol use & $1.50(0.65,3.42)$ & - & $2.33(1.05,5.14)^{*}$ & $1.48(0.77,2.83)$ \\
\hline Alcohol dependence & $1.76(0.53,5.80)$ & - & $0.78(0.15,3.99)$ & - \\
\hline No active transport & $0.31(0.10,0.98)^{*}$ & $0.36(0.11,1.15)$ & $2.62(1.58,4.35)^{* * *}$ & $2.43(1.46,4.06)^{* *}$ \\
\hline Sedentary behaviour & $2.64(0.96,7.25)$ & - & $1.11(0.57,2.27)$ & - \\
\hline
\end{tabular}


Table 2 (continued)

***P $<0.001$, ** $\mathrm{P}<0.01,{ }^{*} \mathrm{P}<0.05$

Furthermore, the low health care utilization for SB in this study in a low-income country versus high receipt for treatment of SB in high-income countries may call for the integration of mental health into existing primary and community health services to increase access to services for people with mental health problems.

\section{Abbreviations}

AUDIT: Alcohol Use Disorder Identification Test; STATA: Statistics and data; STEPS: STEPwise approach to surveillance; SB: Suicidal behaviour; TC: Total cholesterol.

\section{Supplementary Information}

The online version contains supplementary material available at https://doi. org/10.1186/s13033-021-00483-X.

Additional file 1. Description of study variables

\section{Acknowledgements}

The data source, the World Health Organization NCD Microdata Repository (URL: https://extranet.who.int/ncdsmicrodata/index.php/catalog), is hereby acknowledged.

\section{Authors' contributions}

All authors fulfil the criteria for authorship. SP and KP conceived and designed the research, performed statistical analysis, drafted the manuscript, and made critical revision of the manuscript for key intellectual content. All authors read and approved the final version of the manuscript and have agreed to the authorship and order of authorship for this manuscript. Both authors read and approved the final manuscript.

\section{Funding}

Not applicable.

\section{Availability of data and materials}

The data for the current study are publicly available at the World Health Organization NCD Microdata Repository (URL: https://extranet.who.int/ncdsm icrodata/index.php/catalog).

\section{Declarations}

\section{Ethics approval and consent to participate}

Ethical approval was granted by the "Malawi National Health Sciences Research and Ethics Committee." Informed written consent was obtained prior to enrolling participants into the study using the "WHO NCD STEPS survey consent form".

\section{Consent for publication}

Not applicable.

\section{Competing interests}

The authors declare that they have no competing interests.

\section{Author details}

${ }^{1}$ ASEAN Institute for Health Development, Mahidol University, Salaya, Phutthamonthon, Nakhon Pathom, Thailand. ${ }^{2}$ Department of Research Administration and Development, University of Limpopo, Turfloop, South Africa.
${ }^{3}$ Department of Psychology, University of the Free State, Bloemfontein, South Africa. ${ }^{4}$ Department of Psychology, College of Medical and Health Science, Asia University, Taichung, Taiwan.

Received: 21 June 2020 Accepted: 28 May 2021

Published online: 06 June 2021

\section{References}

1. World Health Organization (WHO). Suicide; 2019. https://www.who.int/ news-room/fact-sheets/detail/suicide. Accessed 2 June 2020.

2. Joe S, Stein DJ, Seedat S, Herman A, Williams DR. Nonfatal suicidal behavior among South Africans: results from the South Africa Stress and Health Study. Soc Psychiatry Psychiatr Epidemiol. 2008;43(6):454-61. https://doi. org/10.1007/s00127-008-0348-7.

3. Borges G, Nock MK, Haro Abad JM, Hwang I, Sampson NA, Alonso J, et al. Twelve-month prevalence of and risk factors for suicide attempts in the World Health Organization World Mental Health Surveys. J Clin Psychiatry. 2010;71(12):1617-28. https://doi.org/10.4088/JCP.08m04967blu.

4. Gureje O, Kola L, Uwakwe R, Udofia O, Wakil A, Afolabi E. The profile and risks of suicidal behaviours in the Nigerian Survey of Mental Health and Well-Being. Psychol Med. 2007;37(6):821-30. https://doi.org/10.1017/ S0033291707000311.

5. Jordans M, Rathod S, Fekadu A, Medhin G, Kigozi F, Kohrt B, et al. Suicidal ideation and behaviour among community and health care seeking populations in five low- and middle-income countries: a cross-sectional study. Epidemiol Psychiatr Sci. 2018;27(4):393-402. https://doi.org/10. 1017/S2045796017000038.

6. Bruffaerts R, Demyttenaere K, Hwang I, Chiu WT, Sampson N, Kessler $\mathrm{RC}$, et al. Treatment of suicidal people around the world. Br J Psychiatry. 2011;199(1):64-70. https://doi.org/10.1192/bjp.bp.110.084129.

7. World Health Organization (WHO). Suicide in the world. Global Health Estimates, 2019. https://apps.who.int/iris/bitstream/handle/10665/ 326948/WHO-MSD-MER-19.3-eng.pdf. Accessed 2 June 2020.

8. Mwale CM, Mafuta C. Annual Prevalence of Suicide in Malawi; 2019. https://sjog.uk/pdf/Research/Suicide-Prevalence-in-Malawi.pdf. Accessed 2 June 2020.

9. World Factbook. Malawi; 2020. https://www.cia.gov/library/publications/ the-world-factbook/geos/mi.html. Accessed 2 June 2020.

10. Dendup T, Zhao Y, Dorji T, Phuntsho S. Risk factors associated with suicidal ideation and suicide attempts in Bhutan: an analysis of the 2014 Bhutan STEPS Survey data. PLoS ONE. 2020;15(1):e0225888. https://doi.org/10. 1371/journal.pone.0225888.

11. Scottish Government Social Research (2008). Risk and Protective Factors for Suicide and Suicidal Behaviour: A Literature Review; 2003. https:// dspace.stir.ac.uk/bitstream/1893/2206/1/Suicide\%20review\%5b1\%5d. pdf. Accessed 2 June 2020.

12. Scott KM, Hwang I, Chiu WT, Kessler RC, Sampson NA, Angermeyer M, et al. Chronic physical conditions and their association with first onset of suicidal behavior in the world mental health surveys. Psychosom Med. 2010;72(7):712-9. https://doi.org/10.1097/PSY.0b013e3181e3333d.

13. Moazzami K, Dolmatova EV, Feurdean M. Suicidal ideation among adults with cardiovascular disease: the National Health and Nutrition Examination Survey. Gen Hosp Psychiatry. 2018;51:5-9. https://doi.org/10.1016/j. genhosppsych.2017.12.001.

14. Angelakis I, Gillespie EL, Panagioti M. Childhood maltreatment and adult suicidality: a comprehensive systematic review with meta-analysis. Psychol Med. 2019:49(7):1057-78. https://doi.org/10.1017/S003329171 800382.

15. Sorsdahl K, Stein DJ, Williams DR, Nock MK. Associations between traumatic events and suicidal behavior in South Africa. J Nerv Ment Dis. 2011;199(12):928-33. https://doi.org/10.1097/NMD.0b013e3182392c39. 
16. Cheah YK, Azahadi M, Phang SN, Abd Manaf NH. Sociodemographic, lifestyle and health determinants of suicidal behaviour in Malaysia. Psychiatry Res. 2018;261:319-24. https://doi.org/10.1016/j.psychres.2017. 12.086.

17. Elamoshy R, Bird Y, Thorpe LU, Moraros J. Examining the association between diabetes, depressive symptoms, and suicidal ideation among Aboriginal Canadian peoples living off-reserve: a cross-sectional, population-based study. Diabetes Metab Syndr Obes. 2018;11:767-80. https://doi.org/10.2147/DMSO.S184058.

18. Daray FM, Mann JJ, Sublette ME. How lipids may affect risk for suicidal behavior. J Psychiatr Res. 2018;104:16-23. https://doi.org/10.1016/j.jpsyc hires.2018.06.007.

19. Joung Kl, Cho SI. Association of low blood pressure with suicidal ideation: a cross-sectional study of 10,708 adults with normal or low blood pressure in Korea. BMC Public Health. 2018;18(1):200. https://doi.org/10.1186/ s12889-018-5106-5.

20. Uddin R, Burton NW, Maple M, Khan SR, Tremblay MS, Khan A. Low physical activity and high sedentary behaviour are associated with adolescents' suicidal vulnerability: evidence from $52 \mathrm{low}$ - and middle-income countries. Acta Paediatr. 2020:109(6):1252-9. https://doi.org/10.1111/apa.15079.

21. Vancampfort D, Stubbs B, Mugisha J, Firth J, Van Damme T, Smith L, Koyanagi A. Leisure-time sedentary behavior and suicide attempt among 126,392 adolescents in 43 countries. J Affect Disord. 2019;250:346-53. https://doi.org/10.1016/j.jad.2019.03.053.

22. An KO, Jang JY, Kim J. Sedentary behavior and sleep duration are associated with both stress symptoms and suicidal thoughts in Korean adults. Tohoku J Exp Med. 2015;237(4):279-86. https://doi.org/10.1620/tjem.237.279.

23. Breet E, Goldstone D, Bantjes J. Substance use and suicidal ideation and behaviour in low- and middle-income countries: a systematic review. BMC Public Health. 2018;18(1):549. https://doi.org/10.1186/ s12889-018-5425-6.

24. O'Neill S, O'Connor RC. Suicide in Northern Ireland: epidemiology, risk factors, and prevention. Lancet Psychiatry. 2020;7(6):538-46. https://doi. org/10.1016/S2215-0366(19)30525-5.

25. Goldstone D, Bantjes J, Nel D, Stanbridge J, Lewis I. Alcohol use predicts emergency psychiatric unit admission for non-fatal suicidal behaviour in the Western Cape (South Africa): a case-control study. Int J Psychiatry Clin Pract. 2020;24(2):163-72. https://doi.org/10.1080/13651501.2019.1711419.

26. Bang I, Jeong YJ, Park YY, Moon NY, Lee J, Jeon TH. Secondhand smoking is associated with poor mental health in Korean adolescents. Tohoku J Exp Med. 2017;242(4):317-26. https://doi.org/10.1620/tjem.242.317.

27. Weng SC, Huang JP, Huang YL, Lee TS, Chen YH. Effects of tobacco exposure on perinatal suicidal ideation, depression, and anxiety. BMC Public Health. 2016;16:623. https://doi.org/10.1186/s12889-016-3254-z.

28. Peltzer K, Pengpid S. Early substance use initiation and suicide ideation and attempts among school-aged adolescents in four Pacific island countries in Oceania. Int J Environ Res Public Health. 2015;12(10):12291303. https://doi.org/10.3390/ijerph121012291.

29. Pengpid S, Peltzer K. Early substance use initiation and psychological distress among adolescents in five ASEAN countries: a cross-sectional study. Psychol Res Behav Manag. 2019;12:1003-8. https://doi.org/10. 2147/PRBM.S223624.
30. Brewer-Smyth K, Cornelius M, Pohlig RT. Childhood adversity and mental health correlates of obesity in a population at risk. J Correct Health Care. 2016:22(4):367-82. https://doi.org/10.1177/107834581667016.

31. Henriksen CA, Mather AA, Mackenzie CS, Bienvenu OJ, Sareen J. Longitudinal associations of obesity with affective disorders and suicidality in the Baltimore epidemiologic catchment area follow-up study. J Nerv Ment Dis. 2014;202(5):379-85. https://doi.org/10.1097/NMD.0000000000000135.

32. World Health Organization (WHO). NCD Microdata Repository. MalawiSTEPS 2017; 2020. https://extranet.who.int/ncdsmicrodata/index.php/ catalog/629. Accessed 2 June 2020.

33. Australian government. Alcohol screen (AUDIT). http://nceta.flinders.edu. au/files/3314/2257/4957/Right_Mix_3.pdf. Accessed 2 June 2020.

34. Shaikh MA, Lloyd J, Acquah E, Celedonia KL, Wilson ML. Suicide attempts and behavioral correlates among a nationally representative sample of school-attending adolescents in the Republic of Malawi. BMC Public Health. 2016;16(1):843. https://doi.org/10.1186/s12889-016-3509-8.

35. Bachmann S. Epidemiology of suicide and the psychiatric perspective. Int J Environ Res Public Health. 2018;15(7):1425. https://doi.org/10.3390/ijerp h15071425

36. The World Bank, World Bank Country and Lending Groups; 2020. https:// datahelpdesk.worldbank.org/knowledgebase/articles/906519-worldbank-country-and-lending-groups. Accessed 2 June 2020.

37. Dzamalala CP, Milner DA, Liomba NG. Suicide in Blantyre, Malawi (20002003). J Clin Forensic Med. 2006;13(2):65-9. https://doi.org/10.1016/j.jcfm 2005.08.006.

38. Pompili M, Mancinelli I, Tatarelli R. Stigma as a cause of suicide. Br J Psychiatry. 2003;183:173-4

39. Crabb J, Stewart RC, Kokota D, Masson N, Chabunya S, Krishnadas R. Attitudes towards mental illness in Malawi: a cross-sectional survey. BMC Public Health. 2012;12:541. https://doi.org/10.1186/1471-2458-12-541.

40. Kauye F, Chiwandira C, Wright J, Common S, Phiri M, Mafuta C, MaliwichiSenganimalunje L, Udedi M. Increasing the capacity of health surveillance assistants in community mental health care in a developing country, Malawi. Malawi Med J. 2011;23(3):85-8.

41. Mars B, Burrows S, Hjelmeland H, Gunnell D. Suicidal behaviour across the African continent: a review of the literature. BMC Public Health. 2014;14:606. https://doi.org/10.1186/1471-2458-14-606.

42. PHIA Project. Malawi Population-Based HIV Impact Assessment (MPHIA) 2015-2016; 2016. https://phia.icap.columbia.edu/wp-content/uploads/ 2016/09/MALAWI-Factsheet.FIN_.pdf. Accessed 2 June 2020.

43. Komiti A, Judd F, Grech P, Mijch A, Hoy J, Lloyd JH, Street A. Suicidal behaviour in people with HIV/AIDS: a review. Aust N Z J Psychiatry. 2001;35(6):747-57. https://doi.org/10.1046/j.1440-1614.2001.00943.x.

44. Eriksson M, Glader EL, Norrving B, Asplund K. Poststroke suicide attempts and completed suicides: a socioeconomic and nationwide perspective. Neurology. 2015;84(17):1732-8. https://doi.org/10.1212/WNL.00000 00000001514.

\section{Publisher's Note}

Springer Nature remains neutral with regard to jurisdictional claims in published maps and institutional affiliations.

\footnotetext{
Ready to submit your research? Choose BMC and benefit from:

- fast, convenient online submission

- thorough peer review by experienced researchers in your field

- rapid publication on acceptance

- support for research data, including large and complex data types

- gold Open Access which fosters wider collaboration and increased citations

- maximum visibility for your research: over 100M website views per year
}

At BMC, research is always in progress.

Learn more biomedcentral.com/submissions 